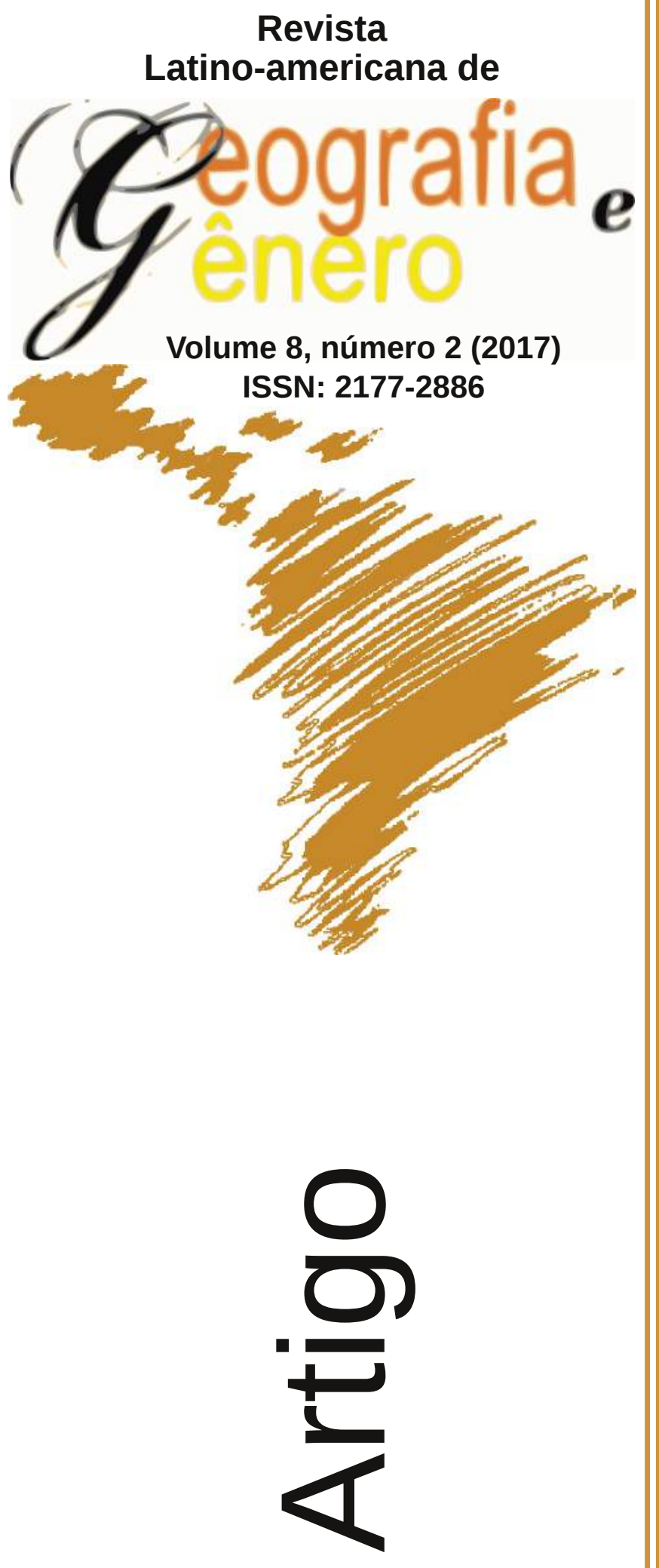

\title{
Pegação: Corpo, Normas, Práticas e Discursos
}

Cruising: Cuerpo, Normatividad, Practicas y

Discursos

Cruising: Body, Normativity, Practices and Discourses

Walter Aristóteles Oliveira Miez

Universidade Federal de Minas Gerais - Brasil waltermiez@gmail.com

\section{Sônia Regina Corrêa Lages}

Universidade Federal de Juiz de Fora - Brasil soniarclages@gmail.com

Como citar este artigo:

MIEZ, Walter Aristóteles Oliveira; LAGES, Sônia Regina Corrêa. Pegação: Corpo, Normas, Práticas e Discursos. Revista Latino Americana de Geografia e Gênero, v. 8, n. 2, p. 337-349, 2017. ISSN 21772886.

Disponível em:

http://www.revistas2.uepg.br/index.php/rlagg 


\title{
Pegação: Corpo, Normas, Práticas e Discursos
}

\author{
Cruising: Cuerpo, Normatividad, Practicas y Discursos
}

Cruising: Body, Normativity, Practices and Discourses

\begin{abstract}
Resumo
Considera-se como pegação uma complexa rede, transgressora, constituída por pessoas homossexuais, ou não, e suas práticas homoeróticas, envolvendo espaços públicos, mercados sexuais, anomia, impessoalidade, e que suscitam afetividades, desejos, insegurança, prazer, culpa. O método fez uso de revisão bibliográfica. Conclui-se que a relação entre heteronormatividade e pegação se dá por meio de duas vias: (1) a pegação subverte a norma, apresentando-se como desviante ao ideal regulatório de sexualidade; (2) a pegação aparece como única possibilidade para que sujeitos vivenciem experiências homoeróticas sem sustentar necessariamente uma identidade homossexual.
\end{abstract}

Palavras-Chave: Pegação; Homossexualidade; Norma; Espaço Público.

\section{Resumen}

Se considera como cruising una compleja red, transgresora, constituida por personas homosexuales, o no, y sus prácticas homoeróticas, incluyendo espacios públicos, mercados sexuales, anomia, impersonalidad, y que suscitan afectividades, deseos, inseguridad, placer, culpa. El método se basó en una revisión bibliográfica. Se concluyó que la relación entre heteronormatividad y cruising se produce a través de dos vías: (1) el cruising subvierte la norma, presentándose como desviación del ideal regulatorio de la sexualidad; (2) el cruising aparece como única posibilidad para que los sujetos tengan experiencias homoeróticas sin tener necesariamente una identidad homosexual.

Palabras-Clave: Cruising; Homosexualidad; Norma; Espacio Público.

\begin{abstract}
Cruising is considered as a complex network, transgressive, consisting of homosexual people, or not, and their homo-erotic practices, involving public spaces, sexual markets, anomie, impersonality, and it raises affections, desires, insecurity, pleasure, guilt. The method used in this research was a literature review. We concluded that the relation between heteronormativity and cruising occurs through two pathways: (1) the cruising subverts the norm, posing as deviant from the normative ideal of sexuality; (2) the cruising appears as the only chance for individuals to experience homo-erotic experiences without necessarily sustaining a homosexual identity.
\end{abstract}

Keywords: Cruising; Homosexuality; Normativity; Public Space. 


\section{Introdução}

A maioria dos trabalhos produzidos sobre a sexualidade, no campo da psicologia social, está relacionado às construções sócio-históricas de papéis masculinos e femininos, sexualidades e identidades de gênero dissidentes, dos quais podemos destacar referências como MacRae (2005) e Prado e Machado (2008). Porém, em se tratar de práticas sexuais dentro do homoerotismo, a área que mais se debruça sobre esses estudos é a antropologia, como faz Parker (2002) em seu livro Abaixo do Equador, bem como Teixeira (2003) e Pocahy (2011), antropólogos que enriquecem esses estudos, valendo-se, principalmente, da etnografia.

Segundo Teixeira (2003), a pegação é nomeadamente a experiência sexual em que desconhecidos buscam o sexo casual sem qualquer ganho financeiro por alguma das partes, o que a diferencia da prostituição. Tal prática costuma ocorrer em determinados locais, dos quais se pode ter conhecimento tanto a partir da casual inserção do sujeito naquele espaço, como através de relatos de outros sujeitos de sua rede de socialização que tem conhecimento do lugar. Alguns exemplos desses lugares são: parques, banheiros e praias (espaços públicos); saunas, cinemas pornôs e dark-rooms (espaços privados). Para o autor, essas experiências que se iniciam fragmentadas e isoladas expõem que nem sempre essas primeiras experimentações derivam de uma vontade clara de vivenciar uma experiência homoerótica. A primeira entrada em um local de pegação pode ocorrer 'acidentalmente', desconhecendo o que de fato se passa por lá, mesmo que esse sujeito tivesse curiosidade e desejo de se envolver sexualmente com outros homens. Com o tempo, a pegação acaba se tornando recorrente ao reconhecer naquele espaço a possibilidade de exercer uma sexualidade que não é permitida no espaço público sem se deparar com retaliações homofóbicas.

Peret (2010, p. 11) destaca que pegação é um termo usado, também, no meio heterossexual para definir a busca de parceiros e/ou parceiras em festas, encontros e danceterias. Porém, esta ganha uma conotação mais específica na sociabilidade gay, remetendo "a procura anônima, imediata e impessoal de satisfação afetiva e/ou sexual, geralmente em cantos discretos e/ou fechados dentro de ambientes públicos".

O sexo se constitui como esfera central na construção da cultura e da sociabilidade gay. É justamente ele que se estabelece como elemento que vai tornar estes sujeitos, que têm desejos sexuais por outros homens, como doentes ou pecadores. O sexo torna esses sujeitos transgressores de normativas sexuais que abominam a relação entre pessoas do mesmo sexo. Isso, aliado à sociabilização masculina, que permite o livre exercício da sexualidade, ainda que ancorado em expectativas sociais sobre o ser homem, possibilita que esses sujeitos constituam relações e práticas sociais tendo como seu pilar principal o sexo (PARKER, 2002).

Costa (2010) introduz, ainda, a ideia de territorialização de determinados espaços públicos para práticas homoeróticas. Para o autor, determinados espaços são apropriados de forma tão consolidada que, em determinados horários, são frequentados quase que exclusivamente por sujeitos interessados em sexo casual. 
Para Parker (2002), o constante romper da heteronorma em espaços heterossexuais fortalecem o processo de homossexualização desse espaço, fazendo com que existam experiências homoeróticas em espaços sociais impensáveis.

Entendemos aqui que, para um espaço ser considerado local de pegação, não basta ser utilizado por indivíduos para a prática do sexo casual, é importante que os praticantes se apropriem, num sentido de fazer dali palco para recorrentes experiências sexuais, se possível compartilhadas numa rede de sociabilidade - seja ela numa conversa com os amigos, em redes sociais da Internet ou, até mesmo, em pichações em paredes e portas de banheiros públicos.

A partir desse contexto, com recorte nos estudos sobre pegação, busca-se, neste artigo, enriquecer os trabalhos analíticos sobre homoafetividades, entender como os sujeitos praticantes falam dessa experiência, descobrir como o corpo é compreendido neste espaço e que normas e práticas a sustentam. A revisão bibliográfica sobre o tema é ilustrada pelas narrativas de pessoas que se assumem como homossexuais e que se dispuseram a conversar sobre o assunto e relatar suas experiências.

\section{Método}

Trata-se de uma pesquisa qualitativa, que, valendo-se da revisão bibliográfica como instrumento investigação, nos possibilitou, a priori, a contextualização da pegação a partir de fontes científicas e posteriormente a análise de suas nuances (ALVES-MAZZOTTI, 2002).

Partindo do que nos foi apresentado pelo referencial teórico levantado, chegamos às seguintes categorias interpretativas: (1) identidade e espaços de pegação; (2) normas e práticas; e (3) a linguagem do corpo. Essa divisão, por categorias de análise, irá cadenciar nossa discussão de modo a apresentar três aspectos diferentes e recorrentes na literatura acerca da pegação.

\section{Identidade e Espaços de Pegação}

Segundo Teixeira (2003), as pegações que ocorrem, principalmente em banheiros públicos e parques situados na cidade, não induzem a uma identidade gay aos seus participantes.

A marginalização da homossexualidade está enraizada em um processo histórico que restringia a vivência homossexual aos guetos gays. Isso leva ao surgimento de territórios homoeróticos que possibilitassem a esses sujeitos maneiras de vivenciar experiências homoeróticas, se apropriando, assim, de determinados espaços urbanos para exercerem suas práticas sexuais.

Fry e MacRae (1983), ao desenvolverem seu estudo sobre guetos homossexuais na cidade de São Paulo, sinalizam o surgimento desses espaços na década de 1950 e 1960. Os guetos gays eram, portanto, áreas de convivência onde se pode vivenciar a homossexualidade e, de alguma forma, isso tinha representatividade na construção de uma identidade também.

O homossexual, sendo colocado numa posição de marginalidade em relação ao padrão sexual hegemônico, encontra na criação dos guetos a possibilidade 
de vivenciar sua sexualidade e estruturar uma vida social, organizada de acordo com as suas preferências. Nesses espaços, o indivíduo não precisa utilizar uma máscara que corresponda ao modelo homossexual - másculo discreto, para que seja tolerado diante do seu desvio, ele pode sentir-se à vontade. Ainda que esse ideal de macho tenha sido, e ainda seja, perpetuado dentro de espaços homoeróticos como desejável, desqualificando aqueles que não correspondem a tal papel.

Assim sendo, nesses guetos era comum presenciar casais de mesmo sexo se beijando, trocando carícias, de mãos dadas, socializando com demais homossexuais, etc. Dessa forma, o surgimento de um mercado voltado para o público homossexual, como bares e boates, contribuiu muito para que se pudessem viver, na época, uma liberdade sexual, mesmo que fosse restrita apenas a certos espaços da cidade. Nesse sentido, Peret (2010) e Costa (2010) reafirmam a importância desses espaços para a sociabilidade gay, em especial, em meados do século $\mathrm{XX}$, período muito violento para as vivências homoeróticas.

Em consonância com MacRae (2005), Peret (2010) destaca que os guetos proporcionam bem-estar aos seus frequentadores por despertarem um sentimento de pertença e provocarem a sensação de uma aceitação social, inclusive, auxiliando na construção de uma identidade homossexual. A opressão social pela sexualidade desviante os levam a se ocultar, e o gueto torna-se, então, o lugar onde as pressões são momentaneamente afastadas (FRY e MACRAE, 1983).

A pegação oferece a possibilidade de sujeitos não necessariamente identificados enquanto gays terem experiências homoeróticas. Teixeira chama atenção para o fato de que as interações nos espaços de pegação são importantes nos processos de construção das identidades homoeróticas. Porém, em relação à interlocução entre espaço e identidade sexual percebe-se que boa parte dos frequentadores de espaços de pegação são homens que não se consideram gays, em especial porque "esses locais não 'exigem', digamos assim, essa postura identitária" (2003, p. 12). Inclusive, o fato de boa parte dos praticantes não se reconhecer como homossexuais, pode se configurar um atrativo a mais para a prática da pegação.

Os motivos que levam os sujeitos a realizar pegação são múltiplos, mas, a facilidade de conseguir experiências sexuais diversas, de forma rápida, fácil e anônima configuraram-se como os principais.

Assim, numa sociedade marcada, ainda, pela repressão à sexualidade não heterossexual, as práticas de pegação se consolidam, então, como uma possibilidade a homens que têm que conviver com uma vida dupla: uma que corresponda ao papel social que lhe é atribuído e outra que atenda aos seus desejos.

\section{Normas e Práticas}

A normatização da sexualidade nos obriga a exercê-la apenas entre quatro paredes, porém, a pegação realizada em ambientes públicos ganha contornos de uma transgressão social tensionando essa normativa, já que o "olhar vigilante do controle social na sociedade pode ser transformado no olhar do 
desejo e na possibilidade de sedução nos ambientes urbanos" (PARKER, 2002, p. 90).

Peret nos faz pensar na identidade sexual dentro de um contexto de práticas de pegação, possibilitando-nos compreender que o interesse na experiência sexual é muito mais importante que qualquer vínculo identitário. Independentemente de o sujeito compartilhar de uma identidade gay, a pegação pode acontecer e, para isso, basta o indivíduo sentir-se sexualmente atraído por outro do sexo masculino, ou enxergar nesse envolvimento sexual algum tipo de prazer. A pegação pode interessar a sujeitos independentemente de se reconhecerem homossexuais ou bissexuais, ela acontece com o intuito de satisfazer um desejo sexual, seja encontrando na pegação a única forma de trazê-lo à prática, seja encontrando na pegação uma possibilidade de torná-lo ainda mais interessante - colocando a heteronormatividade em suspensão.

Os ambientes de pegação, muitas vezes, são de conhecimento das autoridades, que podem tentar transformá-los em objeto de campanhas pela moralidade pública, como fazem, às vezes, com a prostituição feminina (PARKER, 2002).

Segundo Costa (2010), a prática pode vir acompanhada de complicações, tais como: roubo, extorsão, furto, atentado e violência cometidos por sujeitos participantes ou não da pratica da pegação, uma vez que a noite, se por um lado, facilita as práticas homoeróticas, devido à circulação de diferentes desviantes sociais, por outro, nesses mesmos lugares, também circulam pessoas em busca de um ganho rápido a qualquer custo, envolvendo roubo, extorsão e violência.

A representação que se tem sobre a prática de pegação dá força à sua leitura como um desvio social. Heilborn (1999) toma essa noção para dizer que enxergá-la como uma prática desviante fortalece a apropriação de espaços urbanos para práticas homoafetivas. Para além disso, não podemos esquecer que, socialmente, há uma normatização da sexualidade que toma por legitimo apenas o sexo heterossexual, de preferência dentro de uma relação monogâmica e, se possível, com fins de procriação, servindo aos interesses da igreja e do Estado, da manutenção da propriedade privada, da defesa da instituição família, etc.

Butler (2006) destaca a relação direta existente entre a norma, a formação e orientação das ações; assim como a normalização desse modelo promove e sustenta convites e coerções sociais. A norma é paradoxal, à medida que funciona tanto para o reconhecimento e construção de laços sociais, como para a exclusão de corpos que não correspondem a determinadas regras, princípios e padrões compartilhados socialmente. A norma apresenta-se num modelo criado a partir da compreensão social de determinado fenômeno, e esse modelo se sustenta por um discurso que o coloca em posição de hegemonia em relação aos demais. E, a partir da normalização de determinado modelo, este é legitimado, colocando numa posição de anormalidade qualquer outro existente.

A hegemonia do padrão heterossexual foi historicamente construída baseando-se nas posições subalternas as quais foram submetidas sexualidades que representavam uma quebra com a heteronormatividade, as chamadas sexualidades dissidentes. Para Prado e Machado (2008), a experiência homossexual coloca em tensão os limites do privado e do público, o que 
justifica o fato de as sexualidades se transformarem em objeto de luta política e social no Brasil dos últimos anos. Assim, a não-heterossexualidade é estigmatizada como sexualidade dissidente e é gravemente repreendida pelo discurso hegemônico heteronormativo. A normalização dessa repressão acontece de forma a combater o deslocar dessas sexualidades que fogem do padrão heterossexual.

Dessa forma, também se legitimou lógicas de opressão como a homofobia, definida por Borrillo (2001, p. 36) como: "la hostilidad general, psicológica y social, respecto a aquellos y aquellas de quienes se supone que desean a individuos de su propio sexo o tienen practicas sexuales con ellos". O autor ainda destaca a existência de uma diferenciação, segregação, e hierarquização das sexualidades que se estabelece baseando-se na valorização de uma orientação sexual hegemônica, heterossexual, em detrimento de outra, homossexual.

Partindo da ideia que existe uma coerção social em relação às experiências sexuais entre homens, essa coerção levaria os sujeitos a encontrar formas alternativas de se relacionarem, desviando do olhar punitivo da sociedade. A pegação pode ser entendida como a reprodução da opressão e da dominação da vida sexual tradicional. A discriminação da homossexualidade, e de qualquer outro desvio sexual, proíbe, dentre outras coisas, o envolvimento sexual entre homens. Dessa forma, essas práticas deveriam se realizar de modo clandestino sob constante ameaça de violência física ou verbal por parte dos espectadores envolvidos, a polícia, ou grupos que desejam purificar a sociedade para os cidadãos respeitáveis (PARKER, 2002).

A pegação aparece para esses homens como uma dinâmica de resistência que subverte os espaços públicos para práticas sexuais socialmente desqualificadas quando não demonizadas. Heilborn (1999, p. 94) toca na representação social da sexualidade, evidenciada nos espaços de pegação como marcada pelo signo da transgressão. Transgressão essa "que dialoga e convive com regras públicas de moralidade sexual, que entre quatro paredes são, no entanto, rompidas".

A pegação adquire um caráter transgressor à medida que o homoerotismo torna-se parte da sexualidade masculina. Espaços públicos se tornaram palco de contatos homoeróticos, como se estivesse conquistando o território inimigo, construindo um mundo gay semi-secreto, transgredindo a decência sexual, dentro da estrutura da sociedade heterossexual. Abre-se a possibilidade da construção de uma paisagem sexual que permite desde flertes a sexos casuais num espaço neutro da vida diária. Valendo-se do anonimato, sujeitos transformam a hostilidade do mundo heterossexual em um campo de possibilidades eróticas (PARKER, 2002).

A homofobia pode, portanto, ser pensada como uma motivadora da pegação à medida que funciona como um dos mecanismos de inferiorização de sexualidades dissidentes e faz com que esses sujeitos se apropriem de determinados espaços para vivenciar sua sexualidade. Porém, tal experiência é heterogênea e ganha outras configurações para sujeitos que, por exemplo, não se sentem coagidos ao publicar a homoafetividade, que frequentam espaços de pegação pela adrenalina que o risco de ser pego the proporciona e pela possibilidade de transar com homens não gays, respectivamente. 
Apesar de reconhecida como uma prática sexual legítima e de ser praticada por muitos, a pegação carrega consigo fortes estigmas dentro da própria comunidade LGBT (Lésbicas, Gays, Bissexuais, Travestis e Transexuais). Ser reconhecido como praticante de pegação pode acarretar em um sentimento de inferioridade diante dos seus pares. Isso faz com que muitos gays não compartilhem isso em suas redes de sociabilidade (TEIXEIRA, 2003).

Segundo Pocahy, a pegação é vista como uma dinâmica execrável tanto pela heteronormatividade, quanto por uma normatividade homo que não hesitam em significar como desprezíveis os espaços de sociabilidade dos que desviam do bom modelo da homossexualidade ou do bom gênero da homossexualidade. Esses lugares passam a significar inferioridade, produzindo "certo enunciado performativo de uma vida triste e miserável", oferecendo a 'punição' (pela exclusão e desqualificação) a essas 'almas perdidas' e esses corpos 'indesejáveis', pelas lentes da hetero e homonormatividade (POCAHY, 2011, p. 95).

A ideia de estabelecer vínculos duradouros, baseados no conceito do amorromântico, levanta alguns questionamentos. A homossexualidade teria a função de ampliar as possibilidades e as formas das pessoas se relacionarem afetivosexualmente? A homossexualidade contraria a reprodução do padrão heteronormativo de relacionamento? $\mathrm{O}$ amor-romântico gay está relacionado à possibilidade de uma vivência da sexualidade sem restrições ou preconceitos?

Ao mesmo tempo em que os praticantes parecem marcados por esse ideal de amor monogâmico, também consideram a pegação como importante para ter um maior número de relações sexuais. Independente da qualidade destas, o critério quantitativo é muito valorizado dentro da cultura gay - reflexo do estímulo e da liberdade sexual que é parte da socialização masculina e vai constituir esses sujeitos enquanto homens.

\section{A Linguagem do Corpo}

Em se tratar de pegação, o corpo sustenta toda a comunicação, já que é através do gestual que o praticante de pegação irá comunicar aos demais o interesse sexual.

De acordo com Peret (2010), nestes espaços, a principal linguagem utilizada é a corporal - olhares, manipulação dos órgãos genitais, dentre outros gestos. Tais movimentos, quando exitosos, podem resultar numa masturbação mútua, sexo oral ou em uma relação sexual completa dependendo do contexto e da disposição de cada sujeito.

O corpo é construído socialmente, de modo que dicotomias como: corpo e mente ou corpo e alma são reducionistas no que diz respeito à sua compreensão. Estas polarizações não contemplam as dimensões históricas e culturais do seu processo de construção, dificultando, assim, a sua percepção enquanto produto de inserções simbólicas (MALUF, 2002). Trazendo a discussão sobre corpo na perspectiva da performatividade, Butler (2002) compreende este como matéria facilmente transformável e aniquilável. O corpo existe, portanto, à medida que se constitui a partir de um determinado discurso.

Dessa forma, compreendemos que os corpos de homens praticantes de 
pegação se moldam a partir de uma discursividade específica - não se trata de qualquer desejo ou prática sexual qualquer, mas daquela que acontece em lugares de pegação. Estes corpos não apenas noticiam o seu desejo nestes espaços, mas também se transformam numa tentativa de atender o que se delimita ali como objeto de desejo e reproduzem lógicas de segregação e hierarquização dos corpos, a partir dessa compreensão normativa de corpo desejável.

O corpo se transforma num espaço de diálogos e disputas e são fundamentais nos espaços de pegação, na sedução e na abordagem de outro sujeito. É através dele que se comunica o seu desejo e, como enfatiza Heilborn (1999, p. 9), "se torna um parâmetro de avaliação da possibilidade e do estágio do vínculo que se está propondo".

Os signos utilizados nos ambientes de pegação para explicitar o interesse por sexo são específicos, tais como: lavar as mãos repetidamente num banheiro; ficar dando voltas em um determinado espaço; coçar as genitálias, dentre outras, possibilitam despistar os outros frequentadores destes espaços que não têm o mesmo objetivo ou mesmo evitar retaliações (TEIXEIRA, 2003, p. 44). Portanto, tal encenação precisa conter uma dupla mensagem: ao mesmo tempo em que precisa ser clara o suficiente para atingir os sujeitos alvos, ela não pode ser escancarada para não dar visibilidade às reais intenções.

Costa (2010) trata que os sujeitos praticantes de pegação possuem desejos homoeróticos que podem permear os espaços públicos não só com baixa concentração populacional, como ruas mais escuras da noite, parque, praças e praias, mas, também, naquelas cuja concentração populacional é alta, onde as experiências sexuais se dão de forma mais discreta, como nos banheiros públicos. $\mathrm{O}$ autor destaca que aqueles que não se interessam por esse tipo de experiência, muitas vezes, sequer notam que essas interações ocorrem.

A subalternidade e rechaço de identidades que portam signos associados ao feminino traz a hierarquização de corpos dentro das saunas. Tais construções levam em consideração beleza, vigor e idade, deixando claro quais corpos são atrativos e para quem se vende.

Assim, os ambientes de pegação, apesar do seu caráter transgressor, reproduzem as mesmas lógicas de hierarquização apresentadas no restante da sociedade. Há corpos e, consequentemente, pessoas que são mais valorizadas e desejadas que outras a partir de uma normatização da beleza. Essa hierarquização está diretamente relacionada ao padrão estético vigente na sociedade com a hipervalorização da masculinidade, da juventude, dos corpos atléticos e de grandes pênis. E, quanto mais expostos estiverem esses corpos, como nas saunas, mais as hierarquizações vão operar.

O corpo, sendo construído, moldado e pensado a partir da norma, também sustenta a representação na qual vamos nos ancorar para pensar o gênero. A ênfase cultural é valorizada nas práticas sexuais e nos papéis de gênero, havendo uma distinção simbólica principalmente entre atividade e passividade. Esses conceitos são elaborados informalmente na cultura popular em que ativo é empregado para descrever aquele que penetra ativamente, papel atribuído ao macho que durante o ato sexual introduz seu órgão sexual na fêmea. $O$ conceito de passivo seria utilizado para descrever aquele que é penetrado, que exerce, portanto, o papel designado à fêmea de ser introduzida pelo macho. 
Existe uma relação de dominação nas categorias estabelecidas para designar comportamentos ativos e passivos e tal construção serve de base para a hierarquização de outras categorias na cultura homossexual, estendendo-se, portanto, aos espaços de pegação, como: masculinizado e efeminado. Dentro desses espaços, os mais procurados e desejados sexualmente recebem tal valorização por se aproximarem de um padrão hegemônico masculino construído sócio-historicamente: homens jovens, belos, másculos e viris (PARKER, 2002).

Para Poça (2011), a hierarquia dos corpos e dos prazeres tem sua força baseada na gestão higienista e purista do corpo e da sexualidade sobre o envelhecimento. Simões (2004) ainda enfatiza que a preferência pela juventude, em detrimento da velhice, é recorrente na história das concepções ocidentais sobre envelhecimento, ou, pelo menos, constituem sentimentos disseminados na chamada cultura de consumo contemporânea, e este padrão acaba sendo reproduzido e intensificado pela cultura gay dos centros urbanos e das metrópoles. O hedonismo exacerbado e o culto aos atributos físicos, capazes de suscitar atração e desejo, parecem fazer com que tudo gire em torno de um mercado sexual hierarquizado por critérios de juventude e beleza.

Aqueles não são contemplados com nenhuma característica pertencente ao padrão hegemônico carregariam os "estereótipos derivados da depreciação de sua atratividade como parceiros sexuais desejáveis e da decorrente marginalização" pelos mais jovens, belos, viris. Restaria a esses apenas contentar-se com a observação das práticas em ambientes de pegação, ou valer-se do sexo com garotos de programa (SIMÕES, 2004, p. 418).

Braz (2009, p. 7) verificou a valorização da masculinidade na contramão de elementos relacionados à feminilidade e constatou que a maioria dos perfis cadastrados em sites para encontros sexuais buscava homens definidos como 'macho', como postura masculina e sem trejeitos ou afetações. De acordo com o autor, apresentar-se como 'discreto', 'fora do meio' e, sobretudo 'não afeminado' era uma forma de se tornar mais valorizado sexual/afetivamente.

O corpo dentro do espaço de pegação não é apenas um corpo desejante, mas também político. Esse corpo se comunica através de uma linguagem que não usa a palavra e só quem está inserido naquela rede se significados consegue decodificar; denuncia as retaliações homofóbicas e encontra saídas para colocar em prática desejos condenáveis; é refém da heteronormatividade à medida que reproduz lógicas do ideal de homem, valorizando, especialmente, a virilidade e a juventude; e goza em cima das proibições da homoafetividade e coloca a norma em suspensão, trazendo para o espaço público aquilo que era delegado ao privado, o sexo entre homens.

\section{Considerações Finais}

A vida num sistema urbano nos permite desfrutar de certa invisibilidade, que sustenta uma subcultura homoerótica. Nesse enquadramento, nos é permitido, ainda, dizer de uma erotização do espaço de pegação. O espaço que ao mesmo tempo abriga práticas sexuais dissidentes também é hostil e adquire um significado erótico e sexualizado, em um jogo de caça ou pegação, misturando prazer e perigo. A erotização desse espaço acontece precisamente 
pela sua impessoalidade e imprevisibilidade. O olhar de controle social da sociedade tradicional transforma-se no olhar do desejo e numa possibilidade de sedução que pode objetivar, desde uma quebra da rotina, um passatempo, até experiências sexuais.

Compreendemos que essa dinâmica é derivante das interações estabelecidas nos guetos; acomoda participantes com um posicionamento identitário gay ou não, da mesma forma em que contribui para o processo de formação dessa identidade; e baseia-se em relações anônimas e impessoais.

Partindo da discussão possibilitada pela revisão bibliográfica, compreendemos que a pegação, mesmo dentro da cultura gay, é desqualificada, o que justificaria, também, o jogo do anonimato e o silêncio em que se pautam essa prática. Percebe-se, portanto, certa apropriação de valores normativos, vinculados ao ideal regulatório heterossexista, que julga que os envolvimentos sexuais e/ou afetivos devem ocorrer conforme a moral hegemônica, uma ambiguidade que nos fez perceber a existência do preconceito em relação à imagem dos praticantes de pegação: esses são tidos como promíscuos, não confiáveis, para além de outras normatizações como a compreensão de beleza com a hipervalorização, principalmente, da juventude e da virilidade.

Nesse sentido, a pegação nos aparece como possibilidade de socialização no universo homossexual, é compreendida de forma heterogênea pelos sujeitos praticantes, nos permitindo, assim, analisá-la por diversas lentes: (1) transgressão das normas que regulam nossa sexualidade procurando nos adequar a um padrão heterossexual e dentro de uma moralidade cristã. A prática privilegia uma experiência sexual considerada dissidente, bem como fora da proposta monogâmica e procriadora colocada pela igreja; (2) resposta às retaliações homofóbicas, usufruindo e subvertendo o espaço público para práticas sexuais tidas como dissidentes, tornando-se, inclusive, mais excitante. Por tanto, se não é dada aos sujeitos a possibilidade de publicar qualquer tipo de afeto em relação a outro homem sem receber alguma resposta negativa, esses fazem de espaços públicos para dar vazão ao seu desejo, ainda que sob códigos de anonimato; (3) possibilidade de vivenciar experiências sexuais com outros homens sem precisar assumir, necessariamente, uma identidade sexual, evitando assim a publicidade de uma sexualidade que é compreendida como fora da normativa sexual.

Por fim, destacamos a importância de, em futuras investigações, entender como a prática se dá no universo feminino, bem como suas semelhanças e diferenças em relação ao masculino. Para além disso, é importante pensarmos qual é o lugar destinado às travestis nos ambientes de pegação e como se dá sua relação com os demais participantes. Apesar de, na bibliografia consultada, não haver relatos sobre mulheres e travestis em ambientes de pegação, estudos nesse sentido nos ajudariam a compreender melhor a dinâmica das práticas sexuais dissidentes em um contexto de heterossexualidade hegemônica. 


\section{Referências}

ALVES-MAZZOTTI, Alda Judith. A 'revisão bibliográfica' em teses e dissertações: meus tipos inesquecíveis - o retorno. In: BIANCHETTI, Lucídio; MACHADO, Ana Maria Netto. (Org.). A bússola do escrever: desafios e estratégias na orientação de teses e dissertações. São Paulo: Cortez, 2002, p. $25-44$.

BORRILLO, Daniel. Homofobia. Espanha: Editora Bellaterra. 2001.

BUTLER, Judith. Deshacer el género. Barcelona: Paidós, 2006.

BUTLER, Judith. Cuerpos que importan. Sobre los límites materiales y discursivos del sexo. Buenos Aires: Paidós, 2002.

COSTA, Benhur Pinós da. Geografias das Representações Sobre o Homoerotismo. Revista Latino-Americana de Geografia e Gênero, v. 1, n. 1, p. $21-38,2010$.

FRY, Peter; MACRAE, Edward. O que é homossexualidade. São Paulo, Brasiliense, 1983.

HEILBORN, Maria Luiza. Corpos na cidade: sedução e sexualidade. In: VELHO, Gilberto (org.). Antropologia Urbana. Rio de Janeiro: Editora Zahar. 1999, p. 93 - 102.

MACRAE, Edward. Em defesa do gueto. In: GREEN, James; TRINDADE, Ronaldo (Orgs.). Homossexualismo em São Paulo e outros escritos. São Paulo: Editora UNESP, 2005, p. 291 - 308.

MALUF, Sônia Weidner. Corpo e Corporalidade nas culturas contemporâneas: Abordagens antropológicas. Esboços: Revista do programa de pós graduação em história da UFSC, v. 9, n. 9, p. 87 - 101, 2002.

PARKER, Richard. Abaixo do Equador. São Paulo: Editora Record. 2002.

PERET, Luiz Eduardo Neves. Pegação, Cidadania e Violência: as Territorialidades do Imaginário da População LGBT do Rio de Janeiro. Revista Contemporânea, v. 8 ,n. 1, p. 63 - 76. 2010.

POCAHY, Fernando Altair. Entre vapores e dublagens - Dissidências homoeróticas nas tramas do envelhecimento. 2011. Tese (Doutorado em Educação). Programa de Pós-graduação em Educação. Universidade Federal do Rio Grande do Sul. Porto Alegre, Rio Grande do Sul, Brasil.

PRADO, Marco Aurélio Máximo; MACHADO, Frederico Viana. Preconceito Contra Homossexualidades - A Hierarquia da Invisibilidade. São Paulo: Editora Cortez, 2008.

SIMÕES, Júlio Assis. Homossexualidade masculina e curso da vida: pensando Walter Aristóteles Oliveira Miez, Sônia Regina Corrêa Lages 
idades e identidades sexuais. (2004). In: CARRARA, Sérgio (Org). Sexualidade e saberes: convenções e fronteiras. Rio de Janeiro: Editora Garamond, 2004, p. 415 - 447.

TEIXEIRA, Alexandre Eustáquio. Territórios homoeróticos em Belo Horizonte: um estudo sobre as interações sociais nos espaços urbanos. 2003. Dissertação (Mestrado em Ciências Sociais). Programa de Pósgraduação em Ciências Sociais, Pontifícia Universidade Católica - Minas Gerais, Belo Horizonte. 